\title{
CONTAS NACIONAIS DO TURISMO
}

\author{
Márcio Ferreira Coelho ${ }^{1}$
}

\begin{abstract}
RESUMO: O texto aborda a importáncia da elaboração de um sistema de contas nacionais do turismo, com a finalidade de fornecer uma visãosistemática, comparável e completa da atividade turística. São apresentadas algumas estimativas para 1989 e 1990, em quadros derivados das tabelas das Contas Nacionais do Turismo. Procura-se, também, relacionar o desempenho de alguns agregados da economia nacional com os mesmos agregados da economia turística.
\end{abstract}

PALAVRAS-CHAVE: Contabilidadenacional; produção, consumo e renda turística nacional; gastos públicos e tributação; investimentos turísticos; relaçỏes com o Exterior.

ABSTRACT: This text intends to focus on the importance of the elaboration of a national system of tourism accounts purposing to furnish a systematic, comparable and complete visionof the touristic activity. Some estimates for 1989 and 1990 are presented taken from National Tourism Accounts Tables. It also intends to relate the performace of some aggregates of the national economy to the same aggregates of the tourism economy.

KEY WORDS: National accounts; national touristic production; consumption and income; public expenditures and taxation; touristic investments; foreign affairs.

\section{INTRODUÇÃO}

Sabe-se que a necessidade de se obter cifras ordenadas, que permitissem uma visão agregada dos fenòmenos econômicos, levou à criação dos sistemas de contabilidade social. Tal necessidade parece

1 Mestre em Economia pela Fundação Getúlio Vargas. Professor do Departamento de Turismo e Hotelaria da Universidade Estácio de Sá. Economista da EMBRATUR.

End. para correspondência: EMBRATUR - Rua Mariz e Barros, 13/7 andar CEP 20270 - Rio de Janeiro - RJ - Brasil. 
surgir nos anos 30, quando a economia norte-americana e algumas de suas seguidoras entram em prolongada recessão, levando a se pensar na possibilidade de um planejamento econômico. A partir dai, os governos e responsáveis pelas políticas econômicas se deparam com a necessidade de dispor de dados, que fornecessem uma visão do conjunto, popularizando os sistemas de contas nacionais, ao mesmo tempo que a ONU — Organização das Nações Unidas — esforçava-se para sua padronização.

Da mesma forma, a atividade turística moderna ressente-se de informações sistematizadas e agregadas, além de constituir-se, pelas sua próprias características, de inúmeras inter-relações com outros setores. Esses fatores fazem os usuários de dados turísticos embaralharem-se num caudal de informações.

A elaboração das Contas Nacionais no Brasil teve início por volta de 1947, através da FGV - Fundação Getúlio Vargas, responsável por sua divulgação até recentemente. Posteriormente, essa atividade foi transferida para a FIBGE - Fundação Instituto Brasileiro de Geografia e Estatística, que responde por suas estimativas até os dias de hoje.

O sistema contábil turístico, iniciado em 1980, se configura integrado no sistema de contas nacionais, e o esquema que se propõe, cujos resultados são apresentados a seguir, fundamenta-se, essencialmente, nas atividades econômicas turísticas, tais como a produção, o consumo, a formação bruta de capital fixo e as relações com o resto do mundo.

\section{PRODUÇÃO, CONSUMO E RENDA TURÍSTICA NACIONAL}

As últimas informações sobre as Contas Nacionais do Turismo se referem às estimativas para 1990, quando a produção de bens e serviços turísticos registrou um razoável crescimento $(19,8 \%)$, em relação ao ano anterior.

Uma das características fundamentais do turismo é o seu caráter multidisciplinar, distinguindo-o como um setor ligado a qualquer segmento do sistema econômico. Daí o fato de que muitas das investigações acerca de alguns agregados turísticos tomam como ponto de partida sua delimitação econômica, em termos da "utilização de bens e serviços turísticos pelas unidades turísticas", ou seja, pela ótica do consumo para, a seguir, definir, classificar e avaliar a produção turística como operação econômica, especialmente condicionada à definição do consumo turístico.

Logo, a produção de bens e serviços turísticos, juntamente com as importações turísticas, devem atender a demanda turística, tanto dos residentes e dos não-residentes, quanto ao consumo intermediário das empresas no processo produtivo do turismo.

Dentro deste enfoque, o crescimento da produção de bens e serviços turísticos em 1990 é devido ao aumento do consumo que, em grande parte, é atribuído ao consumo dos residentes (aumento de

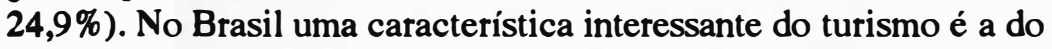
consumo dos residentes superar, aproximadamente, 3,5 vezes o consumo dos não-residentes, em 1990.

\section{Quadro 1}

\begin{tabular}{|c|c|c|c|}
\hline \multirow{2}{*}{ FHA } & 18, & $\$$ & \multirow{2}{*}{ א.m. } \\
\hline & \multicolumn{2}{|c|}{ 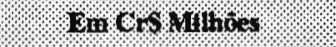 } & \\
\hline Produção de Bens e Serv. Tur. & 1.706 .357 & 2.044 .088 & 19,8 \\
\hline Import. de Bens e Serv. Tur. & 120.927 & 144.443 & 19,4 \\
\hline Consumo Tur. dos Não-Resid. & 228.961 & 238.702 & 4,2 \\
\hline Consumo Tur. dos Resid. & 679.583 & 848.998 & 24,9 \\
\hline Consumo Intermediário & 918.740 & 1.100 .831 & 19,8 \\
\hline
\end{tabular}

Obs.: A preços constantes de 1990.

É interessante notar que este desempenho do consumo dos residentes vem acompanhado de um quadro recessivo da economia brasileira. Uma possível explicação para isso, pode estar no fato de que, em face da concentração de renda verificada ao lớgo da década de 80, aliada à recessão observada em 1990, as familias de alta renda acabam modificando suas preferências entre renda e lazer, optando mais pelo lazer (no caso turismo) em detrimento de outros consumos. 
Com relação à renda turística, as estimativas revelam um acréscimo de $32,7 \%$, no período $1990 / 1989$, revertendo o quadro de queda observado em 1989/1988 (-9,0\%). Os componentes da renda turística, os impostos indiretos deduzidas as subvenções, os salários mais as contribuições sociais e os excedentes mais as amortizações, praticamente mantiveram suas participações relativas na renda em 1990, já que apresentaram um crescimento bastante parecido (cerca de $32,0 \%$ ).

\section{Quadro 2}

\begin{tabular}{|c|c|c|c|}
\hline \multirow{2}{*}{ 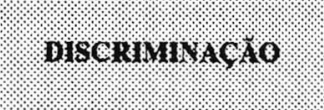 } & 1089 & 1000 & \multirow{2}{*}{ Woripcro } \\
\hline & \multicolumn{2}{|c|}{ Bn Crs Mrilusor } & \\
\hline Renda Turistica & 819.596 & 1.087 .700 & 32,7 \\
\hline Impostos Ind. - Subvenções & 54.159 & 71.789 & 32,5 \\
\hline Salários + Contrib. Sociais & 295.473 & 391.572 & 32,5 \\
\hline Excedentes + Amortizações & 469.964 & 624.339 & 32,8 \\
\hline
\end{tabular}

Obs.: A preços constantes de 1990.

A participação da renda ou o valor adicionado da atividade turística evoluiu 2,3\% da renda nacional em 1989, para 3,4\% em 1990. Com exceção dos impostos indiretos deduzidas as subvenções, que praticamente manteve sua parte no total arrecadado (em torno de $1,8 \%)$, os salários mais as contribuições sociais $(2,1 \%$ para $3,2 \%)$ e os excedentes mais amortizações $(2,5 \%$ para $3,9 \%)$ exibiram uma elevação bem acentuada de um ano para outro em relação ao total.

\section{GASTOS PÚBLICOS E TRIBUTAÇÃO}

Uma conta interessante na contabilidade nacional é a que se refere à administração pública, já que é extremamente importante conhecer os custos públicos do desenvolvimento da atividade turística e, concomitantemente, as receitas geradas por tal processo.
Em linhas gerais, integram essa conta os gastos com promoção, apoio setorial, ex ploração de empresas turísticas estatais, fiscalização da atividade etc., não se considerando os custos de investimento, em virtude de que tais aportes são considerados como formação bruta de capital fixo.

\section{Quadro 3}

\begin{tabular}{|c|c|c|c|}
\hline \multirow{2}{*}{ 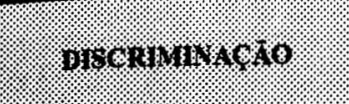 } & $14 \%$ & $1 \%$ & \multirow{2}{*}{ \% } \\
\hline & \multicolumn{2}{|c|}{ 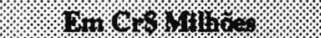 } & \\
\hline Gastos Públ. Bens e Serv. Tur. & 69.097 & 75.872 & 9,8 \\
\hline Subsídios & 6.560 & 8.473 & 29,2 \\
\hline Transferências às Empresas & 3.578 & 4.501 & 25,8 \\
\hline Gastos no Exterior & 312 & 331 & 6,1 \\
\hline Tributos & 212.659 & 264.785 & 24,5 \\
\hline
\end{tabular}

Obs.: A preços constantes de 1990.

Para 1990, essa conta apresenta um saldo positivo, ou seja, os tributos gerados pela atividade turística superam os gastos públicos, merecendo registro o crescimento dos subsídios $(29,2 \%)$, das transferências às empresas $(25,8 \%)$ e dos tributos $(24,5 \%)$.

Com relação ao governo como um todo, as despesas públicas com bens e serviços turísticos correspondem a $4,6 \%$ do total do consumo da administração pública, enquanto os tributos gerados pela atividade turística atingem 3,0\% do total dos tributos em 1990.

O saldo positivo apresentado pelas contas públicas se reveste de suma importância, já que as ações de política turística estão justificadas por uma rentabilidade orçamentária. Mesmoregistrandoum saldo zero ou negativo, os benefícios econômicos e sociais que o turismo produz $\mathrm{e}$ as externalidades positivas podem aconselhar o Estado a dedicar importantes dotações de seu orçamento público ao turismo. 


\section{FORMAÇÃO BRUTA DE CAPITAL FIXO}

A formação bruta de capital do turismo ou investimentos turísticos é uma conta de acumulação e se refere a bens de ativos fixos situados em territótio nacional. A formação de capital pode ser efetuada em construção de hotéis, equipamentos complementares, infraestrutura básica realizada pelo Estado, construção de outras unidades habitacionais turísticas etc., incluindo-se as origens de tais investimentos, bem como as instituições ou agentes econômicos causadores da formação bruta de capital fixo.

No Brasil, ao longo de 1990, os investimentos turísticos cresceram 32,3\% em relação ao ano anterior, sendo parte financiada pelas poupanças e parte pelos investimentos turísticos estrangeiros. Estes investimentos turísticos corresponderam a 3,9\% do total dos investimentos, bem acima dos 2,3\% alcançados em 1989.

\section{Quadro 4}

\begin{tabular}{|c|c|c|c|}
\hline \multirow{2}{*}{ 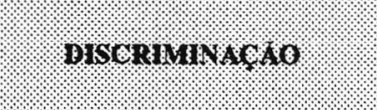 } & $18 \%$ & 1400 & \multirow{2}{*}{ Varvingar } \\
\hline & \multicolumn{2}{|c|}{ Encts Milloes } & \\
\hline Formaçâo Bruta de Capital Fixo & 204.707 & 270.837 & 32,3 \\
\hline Poupança Bruta & 199.311 & 263.795 & 32,3 \\
\hline Investimento Tur. Estrangeiro & 5.396 & 7.042 & 30,5 \\
\hline
\end{tabular}

Obs.: A preços constantes de 1990.

\section{OPERAÇÕES COM O RESTO DO MUNDO}

Esta conta trata de uma simplificação do balanço de pagamentos turísticos, ou seja, o marco exterior do turismo (entradas e saídas de divisas), que tem interessado sempre aos governantes dos países, já que muitos deles estimulam o crescimento do turismo para equilibrar, na margem, o balanço de pagamentos, ampliando as receitas em divisas aportadas pelo turismo. Essa conta se equilibrará com um 32 saldo, positivo ou negativo, conforme o movimento turístico no decorrer de um dado período, e em razão da receita proporcionada pelo turismo seja superior aos pagamentos ou vice-versa.

Em 1990, a conta turismo registrou um saldo negativo em torno de U\$ 115 millhões, apesar das receitas geradas pelo turismo internacional terem crescido cerca de $18 \%$ em relação a 1989 , e a relação receitas turísticas/exportações terem evoluído de 3,5\% em 1989 para 4,6\% em 1990.

Por outro lado, esse saldo negativo deve-se ao excepcional aumento das despesas com turismo internacional, em torno de $108 \%$, elevando a relação despesas turísticas/importações de 4,1\% em 1989 para 7,6\% em 1990.

\section{Quadro 5}

\begin{tabular}{|c|c|c|c|c|c|c|}
\hline \multirow{3}{*}{ 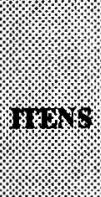 } & \multicolumn{3}{|c|}{ 1018 } & \multicolumn{3}{|c|}{ o } \\
\hline & Naconal & Tursino & $\%$ & Macronal & $11 \%$ sno & $\%$ \\
\hline & 84 & $8(8)$ & $\mathrm{H} / \mathrm{A}$ & (C). & (0). & $8 \%$ \\
\hline Export. & 34.392 & 1.224 & 3,5 & 31.414 & 1.444 & 4,6 \\
\hline Import. & 18.263 & 751 & 4,1 & 20.362 & 1.559 & 7,6 \\
\hline
\end{tabular}

\section{COMENTÁRIOS FINAIS}

O sistema das contas nacionais do turismo é um instrumento metodológico de grande valor para avalição dos efeitos derivados das políticas econômica e social dos países. É óbvio que, como aqui apresentado, trata-se de uma visão bastante resumida e simplificada do sistema contábil vinculado à atividade turística. Entretanto, o objetivo que se pretende alcançar, através de uma linguagem homogênea e comparável, é facilitar diferentes tipos de trabalho de análise e projeção, além de produzir uma medida da dimensão da política turstica nacional, em função de alguns agregados da economia nacional.

Outro aspecto a ser observado é que os resultados apresentados originam-se de uma relação direta com os de outras atividades econô- 
micas e da aplicação da análise insumo-produto da economia turística nacional, o que significa poder quantificar os efeitos diretos, indiretos e induzidos pelo turismo.

\section{BIBLIOGRAFIA}

CONJUNTURA ECONÓMICA. 1991. Rio de Janeiro, FGV, julho.

EMBRATUR. Instituto Brasileiro de Turismo. Sistema de contas nacionais do turismo: análise econômica. Rio de Janeiro: EMBRATUR. Métodos de estimativa dos impactos do turismo na economia brasileira. Rio de Janeiro: EMBRATUR.

ORGANIZACIÓN MUNDIAL DEL TURISMO. 1983. Ensayo para determinar las actividades económicas del turismo en el marco de la contabilidad nacional. (Addéndum B.5.2.1, abril) 